\title{
Evaluating best practices when interviewing stakeholders during design
}

\section{Mr. Ibrahim Mohedas, University of Michigan}

Ibrahim Mohedas is currently a Ph.D. candidate in the Department of Mechanical Engineering at the University of Michigan. He received his B.S. in mechanical engineering from the University of Texas at Austin in 2011. His research focuses on the design of medical devices for resource limited settings, particularly related to the use of design ethnography in developing these technologies. He works in the Laboratory for Innovation in Global Health Technology (LIGHT) and is co-advised by Shanna Daly and Kathleen Sienko.

\section{Dr. Shanna R. Daly, University of Michigan}

Shanna Daly is an Assistant Professor of Mechanical Engineering at the University of Michigan. She has a B.E. in Chemical Engineering from the University of Dayton (2003) and a Ph.D. in Engineering Education from Purdue University (2008). Her research focuses on strategies for design innovations through divergent and convergent thinking as well as through deep needs and community assessments using design ethnography, and translating those strategies to design tools and education. She teaches design and entrepreneurship courses at the undergraduate and graduate levels, focusing on front-end design processes.

\section{Dr. Kathleen H. Sienko, University of Michigan}

Kathleen H. Sienko is a Miller Faculty Scholar and Associate Professor of Mechanical and Biomedical Engineering at the University of Michigan (UM). She earned her Ph.D. in 2007 in Medical Engineering and Bioastronautics from the Harvard-MIT Division of Health Science and Technology, and holds an S.M. in Aeronautics \& Astronautics from MIT and a B.S. in Materials Engineering from the University of Kentucky. She directs the UM Global Health Design Initiative, Sensory Augmentation and Rehabilitation Laboratory (SARL) and the Laboratory for Innovation in Global Health Technology (LIGHT), and codirects the UM Center for Socially Engaged Design. Prof. Sienko has led efforts at the University of Michigan to incorporate the constraints of global health technologies within engineering design at the undergraduate and graduate levels. She is the recipient of a CAREER Award from the National Science Foundation, a Teaching Innovation Prize from the UM Provost, and a UM Undergraduate Teaching Award. While at MIT, she was a winner of the MIT \$50K Entrepreneurship Competition.

\section{Grace Louise Cravens}

Grace Cravens is a junior undergraduate student at the University of Michigan studying Industrial \& Operations Engineering. She is from St. Joseph, MI, and has worked for Sienko Research Group since 2013.

\section{Ms. Linh Huynh}




\section{Evaluating best practices when interviewing stakeholders during design}

\section{Introduction}

Design is a critical component of engineering students' education and an essential skill in engineering $^{1,2}$. Human-centered design processes are increasingly included in engineering education as evidence has demonstrated the success of these approaches in product design ${ }^{3}$. During front-end design phases, particularly problem definition, requirements elicitation, and engineering specification development, human-centered design principles promote extensive stakeholder engagement ${ }^{4}$. Engaging with stakeholders, however, is a complex process of which engineering educators lack experience and techniques to teach, and thus, an opportunity exists for more refined and explicit instruction in both engineering design and non-design courses. Prior research on how students interact with stakeholders during design has revealed a mismatch in student behavior and the approaches documented in the design practice literature ${ }^{5-7}$. Additionally, the challenges students face when interacting with stakeholders causes students to interact less with stakeholders over the semester, reducing their exposure to human-centered design methods ${ }^{6,8}$. This body of research indicates the need to better support students in learning how to engage with stakeholders during design including the development of pedagogy, evaluation methods to determine student proficiency and progress, and design tools to support students during design projects.

This study sought to address the lack of evaluation methods by developing a qualitative coding system that differentiates students by their level of sophistication when conducting stakeholder interviews during requirements elicitation. Furthermore, this analysis identifies the key areas in which pedagogy or design tools are most critical.

\section{Background}

Within both industry and academia, human-centered design processes have been emphasized as a method of developing more usable products that better meet the needs and wants of stakeholders 9,10 . Zhang \& Dong, through a review of design literature, identified several characteristics of human-centered design: human beings in a central place, people are understood holistically, it involves a multi-disciplinary collaboration, users are involved throughout the process, and products are made to be more useful, usable, and desirable ${ }^{10}$. This definition of human-centered design emphasizes the need to obtain a deep understanding of stakeholders during design. Interacting with stakeholders during design facilitates more informed design decisions and leads to products that are adapted to specific contexts of use.

A critical time in which stakeholder interaction plays a major role is during the front-end design phases of problem definition, requirements elicitation, and engineering specifications development $^{11-13}$. Studies have shown that in many instances, product failures result from critical errors made during these front-end design phases ${ }^{11,14,15}$. Front-end design phases are characterized by their ill-defined and "fuzzy" nature, due to the high level of uncertainty involved ${ }^{4}$. Goals of stakeholder interaction during these phases include clarification of the design problem, understanding the stakeholders and context of use, and defining product requirements and engineering specifications. Through these interactions, designers strive to remove some of the 'fuzziness' associated with the design problem and generate a more well-defined problem. 
A human-centered design process requires interacting extensively with stakeholders to elicit useful information and then synthesizing it with other information sources to make informed design decisions. This represents the addition of another information source that students must learn to gather, synthesize, analyze, and then apply to their design projects. This type of extensive information processing has been shown to challenge novices in studies outside of engineering ${ }^{16-19}$. These studies have shown that novices tend to not determine the quality and/or validity of information gathered when applying it to problems and they tend to simply apply information directly to problem solving instead of attempting to synthesize various information sources together ${ }^{16-19}$. Studies within engineering courses found similar results when evaluating use of internet sources used by students when developing reports ${ }^{20}$.

While the importance of effective execution of front-end design phases has been established in the literature, research is lacking with regards to how well design students learn these complex processes and their ability to engage stakeholders during information gathering. Of the studies that have looked at how students interact with stakeholders during design, evidence suggests that this interaction is a major point of difficulty. Research has shown that students do not always interact successfully with stakeholders as defined by best practices found in literature ${ }^{5-7}$. Students also struggle to deal with ambiguous information collected from stakeholders, they do not successfully synthesize and analyze the qualitative information gathered during stakeholder interaction, and they struggle to identify the relevant information that should be gathered during interactions ${ }^{8,21,22}$. Additionally, when students are able to gather meaningful information during stakeholder interaction, they do not necessarily apply it in a meaningful way ${ }^{5}$.

In the study below, we focus on stakeholder interviewing as a key source of information during the design process. The importance of effective stakeholder interviews during the design process, particularly during requirements elicitation, has been documented in a range of fields including automotive systems ${ }^{23}$, medical device development ${ }^{24}$, human-computer interaction ${ }^{25}$, and consumer product design ${ }^{26}$. Furthermore, interviewing stakeholders is a practice that spans almost all human-centered design approaches including participatory design, ethnographic fieldwork, contextual design, lead user approach, among others ${ }^{27}$. Despite the importance of interviewing stakeholders during design, remarkably few support structures are available to designers when interviewing or preparing to interview stakeholders ${ }^{28,29}$. This body of literature also documents the challenges associated with interviewing stakeholders such as ensuring that the most important topics are covered during an interview, ${ }^{30}$ asking appropriate questions, ${ }^{31}$ uncovering how people think or feel about certain topics, ${ }^{32}$ and obtaining broader social, political, or cultural factors that may affect the design ${ }^{33}$. Additionally, one must not only consider the challenge of conducting a stakeholder interview but the challenge of planning and preparing for interviews, gathering information from multiple stakeholders, synthesizing this data together, and analyzing it in order to make design decisions.

\section{Research Design}

Study Purpose

The goal of this study was to determine whether engineering design students followed best practices found within the academic literature when interviewing stakeholders during front-end 
design. The research question guiding the work was: What criteria differentiate stakeholder interview quality among student designers?

Interactive Design Task

Student participants were asked to develop product requirements and engineering specifications for a toy aimed at developing children's cognitive development, specifically a child's understanding of cause and effect. Students were provided with standard templates to document the requirements and engineering specifications developed. To complete the task, participants worked for six and a half hours and were given access to a variety of resources as shown below:

- Academic literature: electronic articles on childhood cognitive development

- Books: several books on children's cognitive development

- Guidelines: Consumer Products Safety Commission guidelines for determining proper age ranges for toys

- Observations*: children playing with various toys under parental supervision

- Stakeholder interviews*: various stakeholders including teachers, parents, a doctoral candidate studying cognition, an education expert (Ph.D.), and the director for a toy safety advocacy non-profit

- Standards: ASTM F963-11 (Standard Consumer Safety Specification for Toy Safety) and ASTM F2729-12 (Standard Consumer Safety Specification for Constant Air Inflatable Play Devices for Home Use)

- Benchmarks: numerous toys for young children

*Observations were available for one hour and stakeholder interviews were available for four hours and forty minutes total.

As part of the design task, participants had the opportunity to interview stakeholders who might have valuable information for requirements development. These stakeholders included: parents (two), teachers (two), a safety expert, and cognitive/education experts (two). Additional details of the interactive design task can be found in a prior publications ${ }^{7}$. Participants were allowed to schedule as many interviews as desired during the allotted times with stakeholders and also had the option of interviewing multiple stakeholders at once.

\section{Participants and Context}

Eight students in their fourth year of engineering participated in the design task. Students were recruited via email, using group lists from a mechanical engineering capstone design course. All students had completed or were in the final weeks of their capstone design course. Participants were compensated $\$ 16$ per hour for participation in the study.

For the analysis below, four participants were selected based upon the results of a previous study $^{7}$. Participants were selected based upon the product requirements they had generated during the design task. Participants for this analysis were selected to include the two highest performing participants (1 and 2) and the two lowest performing participants (3 and 4) with respect to the quality of the requirements generated during the design task. 
Data Collection and Analysis

For the analysis presented below, all interviews conducted by participants with stakeholders were audio and video recorded. These interviews were then transcribed for data analysis. Interviews lasted a maximum of 15 minutes each; however participants were free to schedule as many interviews with stakeholders as they desired.

Nvivo 10 was used to analyze all interview transcripts. A deductive coding system was developed based upon a systematic literature review of academic articles on interview methodologies. Articles from a range of fields were collected including software engineering, requirements engineering, business/innovation, participatory design, information/expert systems development, human-centered design, human-computer interaction, among others. The analysis presented in this study is based upon the coding system is displayed in Table 1. Two study members coded all interview transcripts separately using the coding system. Interrater reliability, as measured via Cohen's kappa, ranged from 0.77 to 0.86 across all interviews ${ }^{34}$. A consensus was reached regarding all coding through group discussions.

The coding system allowed us to determine the frequency with which students employed best practices during interviews with stakeholders. Differences between participants with respect to their use of the best practices shown in Table 1 were assessed using Fisher's exact test. Statistical significance was determine at $\mathrm{p}<0.05$.

Table 1: Coding rubric derived from interviewing best practices found within the literature

\begin{tabular}{|c|c|c|}
\hline $\begin{array}{l}\text { Interview Best } \\
\text { Practice from } \\
\text { Literature }\end{array}$ & $\begin{array}{c}\text { Description of Practice in Design } \\
\text { Context }\end{array}$ & Code Description \\
\hline $\begin{array}{l}\text { Develop a Rapport } \\
\text { with the } \\
\text { Interviewee }\end{array}$ & $\begin{array}{l}\text { Designers do not always have the opportunity } \\
\text { to develop long-term relationships with } \\
\text { stakeholders. It is important to develop a } \\
\text { rapport with each interviewee during each } \\
\text { interview session }{ }^{35-37} \text {. }\end{array}$ & $\begin{array}{l}\text { Designer begins the interview with non- } \\
\text { design related questions or small talk. } \\
\text { Designer uses personal questions (when } \\
\text { appropriate) to develop relationship with } \\
\text { stakeholder. }\end{array}$ \\
\hline $\begin{array}{l}\text { Be Flexible \& } \\
\text { Opportunistic }\end{array}$ & $\begin{array}{l}\text { The designer will naturally be unaware of } \\
\text { many areas that might be of design interest } \\
\text { prior to the interview. A flexible approach to } \\
\text { the interview process allows the designer to } \\
\text { recognize these relevant areas and follow-up } \\
\text { with them in the moment }{ }^{37-41} \text {. }\end{array}$ & $\begin{array}{l}\text { Designer probes into a topic area brought up } \\
\text { by a stakeholder (unrelated to the designer's } \\
\text { original question). } \\
\text { Designer adjusts their interview questions / } \\
\text { approach after learning about the stakeholder. }\end{array}$ \\
\hline $\begin{array}{l}\text { Use a Co-Creative } \\
\text { Interview Strategy }\end{array}$ & $\begin{array}{l}\text { Conducting the stakeholder interview in a co- } \\
\text { creative manner will give the stakeholder a } \\
\text { sense of ownership during the development of } \\
\text { requirements, which can lead to better } \\
\text { engagement during the interview and } \\
\text { elicitation of richer information }{ }^{42} \text {. }\end{array}$ & $\begin{array}{l}\text { Designer asks questions or makes comments } \\
\text { that would increase stakeholder's sense of } \\
\text { ownership of the product requirements. }\end{array}$ \\
\hline $\begin{array}{l}\text { Verify the } \\
\text { Conclusions } \\
\text { Drawn from } \\
\text { Interviews }\end{array}$ & $\begin{array}{l}\text { Designers must ensure that the conclusions } \\
\text { they draw from interviews are accurate before } \\
\text { proceeding in the design and should check } \\
\text { with stakeholders prior to finalizing } \\
\text { requirements }{ }^{43,44} \text {. }\end{array}$ & $\begin{array}{l}\text { Designer presents the stakeholder with their } \\
\text { interpretation of the stakeholder's response } \\
\text { for confirmation. } \\
\text { Designer verifies the requirements generated } \\
\text { through interviews. }\end{array}$ \\
\hline
\end{tabular}




\begin{tabular}{|c|l|l|}
\hline $\begin{array}{c}\text { Avoid } \\
\text { Misinterpretations }\end{array}$ & $\begin{array}{l}\text { Misinterpreting an interviewee's responses } \\
\text { can lead to erroneous information being } \\
\text { collected. It is critical to document } \\
\text { interviewee's exact wording or to ensure the } \\
\text { designer understands all responses }\end{array}$ & $\begin{array}{l}\text { Dest5-49. } \\
\text { they fully understand a stakeholder's } \\
\text { response. }\end{array}$ \\
\hline $\begin{array}{c}\text { Use Projective } \\
\text { Questioning } \\
\text { Techniques }\end{array}$ & $\begin{array}{l}\text { Framing questions in the form of stories, } \\
\text { metaphors, and hypothetical situations } \\
\text { generates richer and more detailed } \\
\text { information from stakeholders } 32,50\end{array}$ & $\begin{array}{l}\text { Designer frames questions using: stories, } \\
\text { metaphors, or hypothetical situations. }\end{array}$ \\
\hline $\begin{array}{c}\text { Encourage Deep } \\
\text { Thinking }\end{array}$ & $\begin{array}{l}\text { Deep thinking questions push stakeholders to } \\
\text { analyze and asses their own ideas and } \\
\text { preferences and uncover the deeper meaning } \\
\text { for specific responses leading to more } \\
\text { meaningful information and tacit } \\
\text { information }\end{array}$ & $\begin{array}{l}\text { 22,50,51. } \\
\text { Designer asks question which requires } \\
\text { stakeholder to: analyze, integrate ideas, or use } \\
\text { reasoning. }\end{array}$ \\
\hline
\end{tabular}

\section{Findings}

The findings are presented below. First, we describe the overall results of the coding system as applied to the four participants. Second, we present an analysis comparing Participants 1 and 2 (high performing) with Participants 3 and 4 (low performing) on the individual best practices evaluated in the coding system.

Analysis of the four participants' interview transcripts resulted in the identification of 350 best practices among all participants. In total, participants asked 206 questions across 21 interviews (Table 2). An assessment of the frequency of best practices displayed by participants (best practices per question) begins to differentiate the high performing students ( 1 and 2 ) from the lower performing students (3 and 4).

Table 2: Summary statistics for interview coding analysis

\begin{tabular}{|l|c|c|c|c|}
\hline & Participant 1 & Participant 2 & Participant 3 & Participant 4 \\
\hline Interviews conducted & 7 & 4 & 3 & 7 \\
\hline Questions asked & 54 & 47 & 27 & 78 \\
\hline Questions per interview & 7.7 & 11.7 & 9.0 & 11.14 \\
\hline Best practices identified & 114 & 98 & 21 & 117 \\
\hline Best practices per question & 2.1 & 2.1 & 0.8 & 1.5 \\
\hline
\end{tabular}

Coding results with respect to each individual best practice are displayed in Figure 2. Participants 1 and 2 outperformed Participants 3 and 4 in every category of best practices (Figure 2). Furthermore, there was a statistically significant difference between the pairs of participants in four of the seven categories: 1) encouraging deep thinking among interviewees, 2) verifying conclusions drawn from interviews, 3) using projective questioning techniques, and 4) using a co-creative strategy within the interview. 


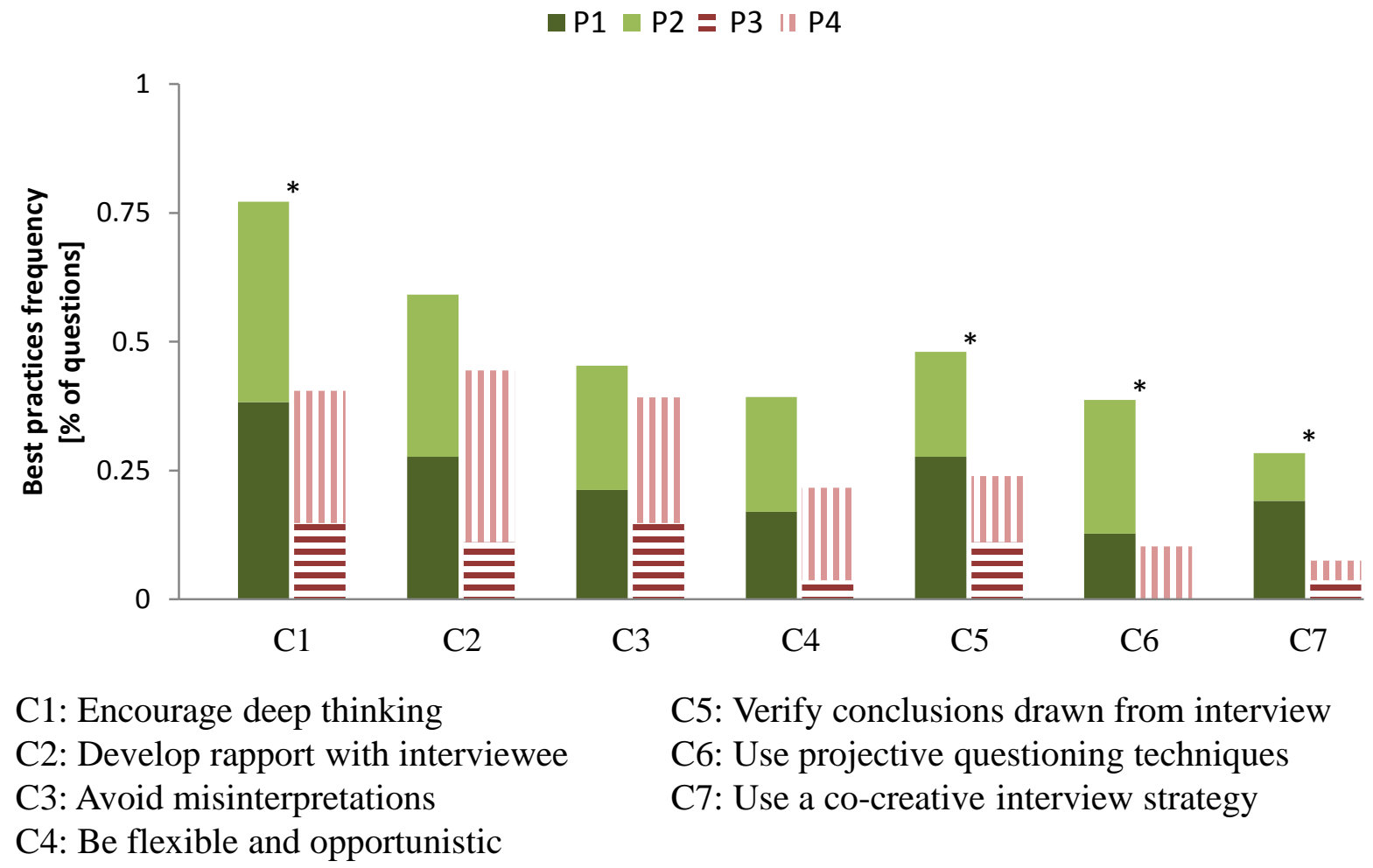

Figure 1: Best practices displayed by participants as a proportion to total questions asked.

\section{Discussion and Implications}

There was a wide range of stakeholder interviewing abilities among the student participants in our design task. Based on our coding and scoring methods, participants who developed higher quality requirements (1 and 2) performed higher quality interviews, while participants who had significantly lower quality requirements ( 3 and 4 ) performed lower quality interviews. While we cannot establish a causal link between students' interviewing abilities and the quality of the requirements they develop (due to mitigating factors such as ability to synthesize information from interviews and other sources, time management during design task, prior experience developing requirements, etc.), prior literature emphasizing the importance of stakeholder interviews and interactions during design suggest that interviewing practices play a prominent role in the development of product requirements ${ }^{42,48,52}$. The results of this study strengthen the probable connection between performing effective requirements elicitation interviews and generating high quality product requirements.

To date, best practices with respect to interviewing stakeholders are scattered among many fields creating a barrier to novices who are attempting to engage with stakeholders during design ${ }^{28,29}$. The coding system developed in this study allowed us to differentiate between high and low quality interviews during design whereas the summary statistics (shown in Table 1) such as questions asked, interviews conducted, or questions per interview did not differentiate the high and low performing students. This provides evidence that a complex task, such as stakeholder interviewing requires a nuanced assessment methodology. The coding system developed could be implemented by instructors in human-centered design courses as both a tool for students to 
use when engaging with stakeholders as well as a method for evaluating students as they learn this complex skill.

The findings also highlighted which best practices best differentiated the high and low performing students. Encouraging deep thinking was a best practice that dramatically differentiated the two pairs of students. Deep thinking questions push stakeholders to analyze situations or beliefs, integrate ideas, or consider multiple factors ${ }^{35-37}$. Participants 1 and 2 displayed this best practice almost twice as often as Participants 3 and 4 (77\% of the time versus $40 \%$ of the time). Deep thinking questions elicit more meaningful data and design pedagogy must clarify to students the difference between deep thinking and superficial questions so that they might better conduct stakeholder interviews ${ }^{37}$. The findings also demonstrate which skills do not differentiate the students, suggesting that they have all learned or been exposed to that particular skill to the same degree. In our coding, developing a rapport with the interviewee and avoiding misinterpretations fall into this category. This suggests that this skill arises naturally, more easily, or that these students have had the same level of practice in garnering this best practice with respect to other best practices. This suggests that instructors might not necessarily need to focus on this best practice when developing pedagogy and guiding students during design courses.

We also saw major differences between students within the best practices of verifying conclusions drawn from interviews and conducting interviews using a co-creative approach. These two best practices are heavily emphasized within design literature, particularly during the front-end design phase of requirements elicitation ${ }^{42-44}$. The disparity between the students within our small sample indicates that these students obtained significantly different knowledge and skill acquisition during their undergraduate career. Improving students skills in requirements elicitation and stakeholder interviewing is a challenge because they are largely learned within project based learning courses (e.g., capstone design courses) and within these courses, project to project differences might lead to very different learning outcomes for students. For example, capstone design projects that are ill-defined and where stakeholders are easily available for interaction would provide students much greater opportunity to develop stakeholder interviewing skills than projects that are rigidly defined and where stakeholders are not easily accessible ${ }^{53}$.

\section{Limitations and Future Work}

Within this study we were not able to control for participants' ability to synthesize the information collected and apply it to requirements development. Therefore, we were not able to establish a causal relationship between a participant's ability to conduct interviews in line with best practices and the final quality of his/her product requirements. Additionally, due to the small sample size and the large variation in student backgrounds, we were not able to ascertain the particular experiences or set of experiences that may have contributed to the variability within students' ability to conduct effective interviews. Future work will seek to simplify the design task and conduct an extensive pre-task questionnaire in order to increase the sample size of students and connect prior experiences to students' ability to conduct effective interviews.

\section{Conclusions}

Human-centered design processes are becoming pervasive in industry and are being taught within many engineering design curricula in academia. As a critical task during requirements 
development and front-end design phases in general, successfully interacting with stakeholders is a crucial ability that students must gain during their undergraduate career. The findings of our research suggest several implications for design education. While most learning in these areas is through experiential project based learning, effort should be taken to bolster this approach with reflective learning practices. Furthermore, the coding structure used in this study derived from best practices found within the academic literature on performing interviews could serve as a basis for developing support tools that students could use within the context of design courses and be used to evaluate student performance and track progress.

\section{Acknowledgments}

This work was supported by the University of Michigan's Rackham Merit Fellows program, the National Science Foundation's Graduate Research Fellowship program, the National Science Foundation's Research Initiation Grants in Engineering Education, and the University of Michigan Center for Research on Learning and Teaching's Investigating Student Learning Grant. The study team thanks the students who volunteered as study participants.

\section{Bibliography}

1. Simon, H. A. The Sciences of the Artificial. (MIT Press, 1996).

2. Dym, C., Agogino, A., Eris, O., Frey, D. \& Leifer, L. Engineering design thinking, teaching, and learning. J. Eng. Educ. 94, 103-120 (2005).

3. Kujala, S. User involvement: a review of the benefits and challenges. Behav. Inf. Technol. 22, 1 - 16 (2003).

4. Ashok, K., David, L., Gupta, A. K. \& Wilemon, D. L. Accelerating The Development Of Technology-Based New Products. Calfornia Manag. Rev. 32, 24-44 (1990).

5. Sugar, W. A. What is so good about user-centered design? Documenting the effect of usability sessions on novice software designers. J. Res. Comput. Educ. 33, $235-250$ (2001).

6. Scott, J. B. The Practice of Usability: Teaching User Engagement Through ServiceLearning. Tech. Commun. Q. 17, 381-412 (2008).

7. Mohedas, I., Daly, S. R. \& Sienko, K. H. Requirements Development: Approaches and Behaviors of Novice Designers. J. Mech. Des. 137, 071407 (2015).

8. Mohedas, I., Daly, S. R. \& Sienko, K. H. Design Ethnography in Capstone Design: Investigating Student Use and Perceptions. Int. J. Eng. Educ. 30, 888-900 (2014).

9. Jokela, T. The standard of User-Centered Design and the Standard Definition of Usability: Analyzing ISO 13407 against ISO 9241-11. in ACM Int. Conf. Proceeding Ser. 53-60 (ACM, 2003).

10. Zhang, T. \& Dong, H. Human-Centred Design: An Emergent Conceptual Model. in Proc. Incl. 1-7 (Royal College of Art, 2009).

11. Cooper, R. G. Predevelopment Activities Determine New Product Success. Ind. Mark. Manag. 17, 237-247 (1988).

12. Khurana, A. \& Rosenthal, S. R. Towards Holistic 'Front Ends' in New Product Development. J. Prod. Innov. Manag. 15, 57-74 (1998).

13. Kim, J. \& Wilemon, D. Focusing the Fuzzy Front-End in New Product Development. 
R\&D Manag. 32, 269-279 (2002).

14. McGuinness, N. W. \& Conway, H. A. Managing the Search for New Product Concepts: A Strategic Approach. R\&D Manag. 19, 297-308 (1989).

15. Davis, A. M. Software Requirements - Objects, Functions, and States. (Prentice Hall, Inc., 1993).

16. Alexandersson, M. \& Limberg, L. Constructing Meaning Through Information Artefacts. New Rev. Inf. Behav. Res. 4, 17-30 (2003).

17. Hultgren, F. \& Limberg, L. A Study of Research on Children's Information Behaviour in a School Context. New Rev. Inf. Behav. Res. 4, 1-15 (2003).

18. Limberg, L. Experiencing Information Seeking and Learning: A Study of the Interaction Between Two Phenomena. Inf. Res. 5, 5-1 (1999).

19. McGregor, J. H. \& Streitenberger, D. C. Do Scribes Learn?: Copying and Information Use. Sch. Libr. Media Res. 1, (1998).

20. Wertz, R. E. H., Purzer, Ş., Fosmire, M. J. \& Cardella, M. E. Assessing Information Literacy Skills Demonstrated in an Engineering Design Task. J. Eng. Educ. 102, 577-602 (2013).

21. Mohedas, I., Daly, S. R. \& Sienko, K. H. Gathering and Synthesizing Information During the Development of User Requirements and Engineering Specifications. in 121st ASEE Annu. Conf. Expo. (2014).

22. Mohedas, I., Daly, S. R. \& Sienko, K. H. Student Use of Design Ethnography Techniques During Front-End Phases of Design. in 121st ASEE Annu. Conf. Expo. (ASEE, 2014).

23. Islam, S. \& Omasreiter, H. Systematic use case interviews for specification of automotive systems. Proc. - Asia-Pacific Softw. Eng. Conf. APSEC 2005, 17-24 (2005).

24. Martin, J. L. \& Barnett, J. Integrating the results of user research into medical device development: Insights from a case study. BMC Med. Inform. Decis. Mak. 12, (2012).

25. Light, A. Y - Adding method to meaning: A technique for exploring peoples' experience with technology. Behav. Inf. Technol. 25, 175-187 (2006).

26. Kuniavsky, M. Observing the user experience: A practitioner's guide to user research. (Morgan Kaufmann Publishers, 2003).

27. Steen, M., Kuijt-evers, L. \& Klok, J. Early user involvement in research and design projects - A review of methods and practices. in 23rd EGOS Colloq. (2007).

28. Moody, J. W., Blanton, J. E. \& Cheney, P. H. A theoretically grounded approach to assist memory recall during information requirements determination. J. Manag. Inf. Syst. 15, 79-98 (1998).

29. Browne, G. J. \& Rogich, M. B. An Empirical Investigation of User Requirements Elicitation: Comparing the Effectiveness of Prompting Techniques. J. Manag. Inf. Syst. 17, 223-249 (2001).

30. Burnay, C., Jureta, I. J. \& Faulkner, S. What stakeholders will or will not say: A theoretical and empirical study of topic importance in requirements engineering elicitation interviews. Inf. Syst. 46, 61-81 (2014).

31. Wetherbe, B. J. C. Executive Information Requirements: Getting It Right. MIS Q. 15, 5165 (1991).

32. Donoghue, S. Projective techniques in consumer research. J. Fam. Ecol. Consum. Sci. 28, 47-53 (2010).

33. Goguen, J. A. \& Linde, C. Techniques for Requirements Elicitation. in 1st IEEE Int. Symp. Requir. Eng. 152-164 (IEEE, 1993). 
34. Hallgren, K. a. Computing Inter-Rater Reliability for Observational Data: An Overview and Tutorial. Tutor. Quant. Methods Psychol. 8, 23-34 (2012).

35. Dieter, G. E. in Eng. Des. 75-115 (McGraw-Hill, 2012).

36. Tsai, W. T., Mojdehbakhsh, R. \& Rayadurgam, S. Experience in capturing requirements for safety-critical medical devices in an industrial environment. in High-Assurance Syst. Eng. Work. 32-36 (IEEE, 1997).

37. Strickland, C. Mining for information: tactics for interviewing. IPCC 2001. Commun. Dimens. Proc. IEEE Int. Prof. Commun. Conf. 349-352 (2001). doi:10.1109/IPCC.2001.971584

38. Nguyen, L., Carroll, J. \& Swatman, P. a. Supporting and monitoring the creativity of IS personnel during the requirements engineering process. in Proc. 33rd Annu. Hawaii Int. Conf. Syst. Sci. (2000). doi:10.1109/HICSS.2000.926899

39. Agarwal, R. \& Tanniru, M. R. Knowledge Acquisition Using Structured Interviewing: An Empirical Investigation. J. Manag. Inf. Syst. 7, 123-140 (1990).

40. Dhillon, J. S., Ramos, C., Wünsche, B. C. \& Lutteroth, C. Designing a web-based telehealth system for elderly people: An interview study in New Zealand. Proc. - IEEE Symp. Comput. Med. Syst. (2011). doi:10.1109/CBMS.2011.5999157

41. Luck, R. Learning to talk to users in participatory design situations. Des. Stud. 28, $217-$ 242 (2007).

42. Scheinholtz, L. A. \& Wilmont, I. Interview patterns for requirements elicitation. Lect. Notes Comput. Sci. (including Subser. Lect. Notes Artif. Intell. Lect. Notes Bioinformatics) 6606 LNCS, 72-77 (2011).

43. Nuseibeh, B. \& Easterbrook, S. Requirements Engineering: A Roadmap. in Conf. Futur. Softw. Eng. 1, 35-46 (ACM, 2000).

44. Firesmith, D. Specifying Good Requirements. J. Object Technol. 2, 77-87 (2003).

45. Wooten, T. C. \& Rowley, T. H. Using anthropological interview strategies to enhance knowledge acquisition. Expert Syst. Appl. 9, 469-482 (1995).

46. Feltovich, P., Spiro, R. \& Coulson, R. in Cogn. Sci. Med. (Evans, D. \& Patel, V.) 11131172 (MIT Press, 1989).

47. Spradley, J. P. in Ethnogr. interview. (Holt, Rinehard and Winston, 1979).

48. Byrd, T. A., Cossick, K. L. \& Zmud, R. W. A synthesis of research on requirements analysis and knowledge acquisition techniques. Manag. Inf. Syst. Q. 16, 117-138 (1992).

49. Dekker, S. W. a, Nyce, J. M. \& Hoffman, R. R. From contextual inquiry to designable futures: What do we need to get there? IEEE Intell. Syst. 18, 74-77 (2003).

50. Rosenthal, S. R. \& Capper, M. Ethnographies in the Front End: Designing for Enhanced Customer Experiences*. J. Prod. Innov. Manag. 23, 215 - 237 (2006).

51. Leifer, R., Lee, S. \& Durgee, J. Deep structures: Real information requirements determination. Inf. Manag. 27, 275-285 (1994).

52. Shahidi, S. \& Kasirun, Z. M. Using Ethnography Techniques in Developing a Mobile Tool for Requirements Elicitation. 2009 Int. Conf. Inf. Manag. Eng. 510-513 (2009). doi:10.1109/ICIME.2009.97

53. Mohedas, I. \& Cravens, G. L. Valuing and engaging stakeholders: The effects of engineering students' interactions during capstone design. in 122nd ASEE Annu. Conf. Expo. (2015). 